\title{
Smart energy management of Wind/PV/Battery renewable energy sources based on IoT
}

\author{
Ahmed Abdul Nasser ${ }^{1}$, Emad Ahmed Mohammed ${ }^{2}$, Ahmed Jadaan Ali ${ }^{3}$ \\ \{ahmednaser@ntu.edu.iq ${ }^{1}$, e.a.mohammed@ntu.edu.iq ${ }^{2}$, ahmed.j.ali@ntu.edu.iq $\left.{ }^{3}\right\}$ \\ Northern Technical University /Technical Engineering College/Computer Engineering Technology, \\ Mosul, Iraq ${ }^{1,2}$ \\ Northern Technical University /Technical Engineering College/ Electrical Power Technology \\ Engineering Mosul, $\mathrm{Iraq}^{3}$
}

\begin{abstract}
The smart grid allows consumers and utility grids to communicate, allowing for the most efficient use of generated energy based on environmental, price, and system technical factors. One of the primary advantages of this system is energy management, which is carried out in conjunction with the internet of things (IoT), with real-time monitoring of devices and control data processing. The purpose of the Internet of Things in this project is to build a smart control system to manage generated electricity among several Nano grids by remotely monitoring generated and used power. A set of multifunction sensors is used to wirelessly sense real-time data and convert it into the necessary format, as well as to help move the sensed data over the network cloud via the 'Internet Connection'. Several slave nodes are present in a microgrid (SN). Every SN serves as its own grid (Nano grid), with two or three independent renewable energy sources connected to the master node of the central control unit (MN). To assure a satisfactory outcome, a prototype was built using solar cells and wind turbines as power sources, with an ARDUINO microcontroller managing and controlling power transfer between slave nodes. The practical results showed a good match between the simulated and practical results.
\end{abstract}

Keywords: IoT, Photovoltaic, Wind turbine, hybrid energy, energy management

\section{Introduction}

The growth in building in addition to increase the in population leads to an increase in the demand for electric power to fill the request. This means that $\mathrm{CO} 2$ emissions from fossil fuels will increase, resulting in more pollution and harm to the environment. However, fossil fuels such as oil, coal, and natural gas are only available in finite quantities. Because it is necessary to keep extracting them, fossil fuels will eventually run out. Although fossil fuels are produced by natural processes, they do not replenish as quickly as they are consumed by humans. As a result, creating energy from these resources has a significant negative impact on our ecosystem, contaminating our air, land, and water. Renewable energy has grown at a higher rate than all other energy sources since 2011. Renewable energy enjoyed again another record-breaking year in 2019 [1], with installed power capacity increasing by more than 200 Gigawatts (GW), the 
greatest increase in history. Renewable energy comes from natural resources that renew in less than a human lifetime without diminishing the planet's resources. Sunlight, wind, rain, tides, waves, biomass, and thermal energy stored in the earth's crust are all resources that are available in some form or another almost everywhere. They're practically indestructible. What's more, they have little impact on the climate or the ecosystem. There have been international campaigns to promote self-sufficient renewable energy systems. This approach has resulted in the development of renewable power generation systems that can generate self-sufficient power using multiple renewable energy sources [2-3]. The most often employed hybrid renewable energy sources are solar and wind energy [4-5]. Because both of these sources of energy are intermittent, an energy storage system (ESS) is required in off-grid applications [6-7]. To ensure an effective transfer of generated power, multiple control mechanisms are used to govern the functioning of hybrid renewable energy systems. The type of energy conversion system and the type of converters utilised at various points in the system determine the system design [8-10]. The microgrid in DC. DC loads and resources make up the majority of a DC microgrid. [11,12]. Pumps, heating, ventilation, and air conditioning (HVAC) systems, fans, elevators, mills, and traction systems all employ DC power in Variable Speed Drives (VSD)[13]. AC Microgrids is the second. Due to the ease with which voltage levels may be changed using low-frequency transformers and the ease with which faults and protection can be handled, this system has dominated the DC system for many years. Furthermore, AC electricity is simple to transport, and most industrial gadgets require AC power. In recent years, AC RESs like as wind turbines, tidal, biogas, and wave turbines have been combined with AC Microgrids [14]. [15]. Hybrid-AC/DCMicrogrid is the third type. This structure combines the advantages of AC and DC microgrids, making it easier to connect AC and DC loads to their respective sources[16].These Microgrids need to be managed monitor and controlled by the central unit to regulate resources and chose appropriate one or combine two sources to meet the demand of the microgrid this operation can be done by using IoT protocol. The Internet of Things (IoT) is concerned with the management of data among devices on a network frame that is available. The Internet of Things (IoT) is a new technology that allows devices to connect with one another via the cloud. IoT embedded devices can provide enhanced functionality while avoiding the complexities of traditional computer-based systems. These systems communicate with the real environment using sensors, and actuators [17][18], kinds are given in Fig 1. IoT devices are used in both hardware and software components, such as Arduino and Raspberry Pi. Over the last few years, the Internet of Things (IoT) has been increasingly popular. The technology itself allows the user the flexibility to a free or paid term for the use of the internet cloud memory. The Internet of Things (IoT) refers to physical objects that are linked to wired and wireless networks [19] via an application programming interface (API). IoT is employed in a variety of industries besides consumer electronics and appliances, including smart cities, healthcare, smart homes, smart cars, smart grid systems, and a variety of other industrial applications [20]. The IoT protocol and microcontroller can be applied to monitor and control the power generation source and connect the sensed parameters like voltage, current and power signals to an application. In [21] IoT is used to produce a cheap solar monitoring system, where this example gives an idea about how to deal with other types of power sources. In [22], the authors proposed an Intelligent Smart Energy Management Systems (ISEMS) architecture for demand-side energy management that takes renewable energy into account. PV-generated data is collected for prediction models in the proposed structural design, which also includes a smart energy management system for load scheduling and an IoT environment enabling the user to access energy details and control. This setup will demonstrate the use of a microcontroller and the Internet of Things protocol to control and monitor several nodes. The authors of the [23] study concentrated their efforts on leveraging 
IoT to control hybrid energy systems. There are different structures for connecting hybrid renewable energy sources that are all alternatives to one another, such as solar energy, wind energy, biofuel, fuel cell, and so on. When hybrid energy sources are deployed for household or commercial use, they must be controlled. As a result of this, the Internet of Things plays a significant role in regulating power flow in the electric system. The issue in demand-side energy management, according to [24], is to maximise the use of renewable energy while reducing power usage. In a smart grid setting with high renewable penetration, an Intelligent Smart Energy Management System (ISEMS) is proposed to address energy demand. The suggested approach compares a number of prediction models for precise energy forecasts with hourly and daily planning. In terms of performance accuracy, the PSO-based SVM regression model outperforms various other prediction models. Finally, using the projected data, the ISEMS experimental setup is demonstrated and assessed with several settings that include user comfort and priority aspects. Integration of the IoT ecosystem is also being developed for user monitoring. In This paper we use inexpensive board and sensors to reduces the cost of the system instead of using expensive and large component for the same purpose. System parts are Arduino UNO board, NODMCU, voltage sensor, current sensor and ESP8266 Wi-Fi Module that helps to process and transfer the sensed data to the Thing speak Cloud. The control unit computes the value loads of all SNs, then it sends a control orders to manage the power among the nodes that had a shortage in its generated power.

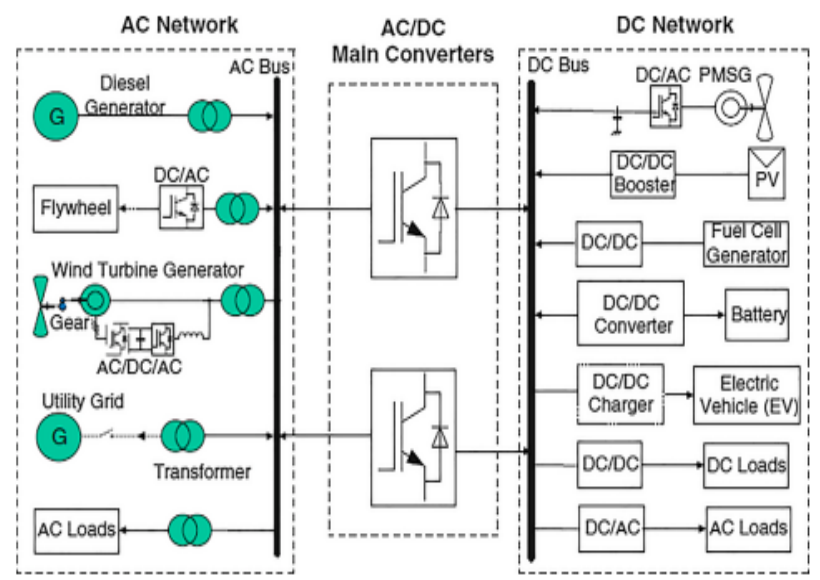

Fig 1. types of microgrid [12]

\section{Structure of Energy Management System}

In the current work, a stand-alone power system has a Microgrid, which is considered as a master node (MN) with three slave nodes (Nano grids), is considered as a base unit for the energy management system. A PV module is connected to the load via a DC-DC boost converter and common DC-bus system. While the wind turbine generator is connected to the load through an AC-DC converter and common DC-bus. In the following paragraphs a brief description of each component of a microgrid.

\subsection{Photovoltaic}


The photovoltaic module consists of photovoltaic cells that are connected in parallel and series [25]. These cells are p-n junctions that are fabricated in thin-film semiconductors such as silicon that enables to converts the light energy into electricity [26]. As the cell exposed to light energy, the photon that hits the cells will be absorbed by semiconducting material as the electron will be flow and creating electricity [27]. An ideal PV cell is modelled as a single diode circuit as shown in Fig 2. The current $I_{P H}$ represents the photocurrent of the cell [28]. $I_{O}$ represents the PV saturation current and while $R_{s h}$ and $R_{S}$ both are intrinsic shut and series resistances of the cell respectively. Both value of $R_{s h}$ and $R_{s}$ are always neglected to simplify the analysis due to the value of $R_{s h}$ is very large and $R_{s}$ is very small [29]. To have a high value of voltage and current, $\mathrm{PV}$ cells are connected to form a module that is usually covered by a cover of glass and mounted together. Then, when the modules are connected parallel and series configurations, they form a PV array. Equus (1 -8) below shows the mathematical model of the PV panel [30-31]

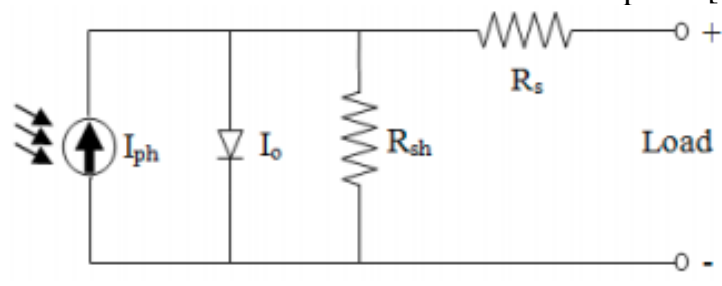

Fig 2. DC equivalent model of solar cell [32].

Thermal Voltage Equation

$V_{T}=V_{B} T_{O P T} / q$

Diode Current Equation

$I_{D}=N_{p} I_{S}\left[e^{\left(V / N_{S}\right)+\left({ }^{I R_{S}} / N_{S}\right) N V_{T} C}-1\right]$

Load Current Equation

$I_{L}=I_{p h} N_{p}-I_{D}-I_{S H}$

Photocurrent Equation

$\left.I_{p h}=\left[\begin{array}{lll}K_{i} & \left(T_{O P T}\right. & -T_{R E F}\end{array}\right)+I_{S C} \quad\right] I_{R R}$

Shunt Current Equation

$I_{S H}=\left(I R_{S}+\mathrm{V}\right) / R_{S H}$

Reverse Saturation Current

$I_{S}=\left[I_{R S}\left(T_{O P T} / T_{R E F}\right)^{3} * q^{2} \mathrm{Eg} / \mathrm{N} K_{B} * e^{\left(1 / T_{O P T}-1 / T_{R E F}\right.}\right)$

Reverse Current Equation

$I_{R S}=I_{S C} /\left[e^{\left(\frac{q V_{O C}}{K C T_{O P T}}\right)}-1\right]$ 
Output Power

$\mathrm{P}=\mathrm{VI}$

The MATLAB Simulink software is used to construct the design of a Photovoltaic based on (18) equations explained in Fig 3. Where: V I stands for Thermal Voltage, while V stands for Operating Voltage. Junction Voltage (V-J). Open Circuit Voltage (V-OC). I PH: Irradiation and junction temperature photocurrent function. I S : Diode Reverse Saturation Current. Short Circuit Current (ISC)). CELL OUTPUT CURRENT (I) T (RFE): Cell's Reference Operating Temperature. T (option): Cell Operating Temperature $\left({ }^{\circ} \mathrm{C}\right)$. Shunt Resistance of Cell (R sh). R (S): Cell Series Resistance. For instance, consider the Energy Band Gap. N is the Optimal Factor. Boltzmann constant $\left(1.3810^{-23} \mathrm{~J} / \mathrm{K}\right)$ : K (B). Current proportionality constant $\left(2.2^{*} 10^{-3}\right), \mathrm{K}(\mathrm{i}) . \mathrm{K}$ $(\mathrm{V})=$ Constant of Voltage Proportionality $(73 * 10-23)$.

$\mathrm{q}$ is the charge of an electron $\left(1.602 \times 10^{-19} \mathrm{C}\right) . \mathrm{N}(\mathrm{S})$ is the number of cells in a series. $\mathrm{N}(\mathrm{P})$ : Number of parallel cells.

Irradiance $\left(1000 \mathrm{~W} / \mathrm{m}^{2}\right)$. G: Irradiance $\left(1000 \mathrm{~W} / \mathrm{m}^{2}\right) . \mathrm{C}$ is the number of cells in a module.

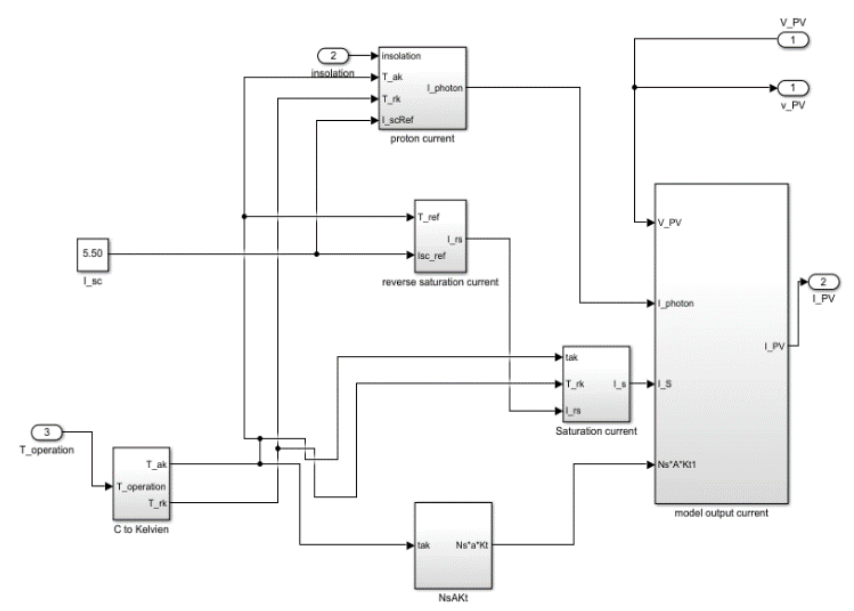

Fig 3. Solar panel construction using MATLAB Simulink.

\subsection{Wind Turbine Generator}

Wind energy is converted into electricity using a wind turbine generator. The rotor, which includes the blades and is connected to the generator through a shaft to convert wind energy to low-speed rotational energy, is one of the three basic components of a wind turbine system. The second component is the generator, which consists of the electrical generator, which includes all control circuits as well as a gearbox that converts the rotating low speed into electric power, and finally, the tower and nacelle, which houses all of the previous components. The axis on which a wind turbine revolves can be classified into two groups. There are two types of axes: horizontal and vertical. The horizontal axis is more familiar and frequent than the vertical axis because it can capture the most amount of wind energy for the time of day and alter its blade pitch angle to avoid high windstorms. (32-33). A wind turbine turns the energy contained in moving air into 
electricity. As indicated in Eqs. (9-11), air density, power coefficient, air density, and turbine swept area are all factors that affect the captured energy,

$P_{m}=0.5 \times \rho \times C_{P} \times V_{m} \times \mathrm{A}$

A wind turbine's tip speed ratio (TSR) is defined as:

$\lambda=\left(w_{m} \times \mathrm{R}\right) / V_{m}$

The rotor power coefficient, represented by $\mathrm{Cp}$, is calculated using the TSR and blade pitch angle $\beta$. The rotor power coefficient can be determined using the following formula:

$C_{P}=P_{\text {rotor }} / P$ wind

Where $\mathrm{P}=$ Mechanical power in the moving air (Watt). $\rho=$ Air density $\left(\mathrm{kg} / \mathrm{m}^{3}\right) \cdot \mathrm{A}=$ Area swept by the rotor blades $\left(\mathrm{m}^{2}\right) . \mathrm{V}=$ Velocity of the air $(\mathrm{m} / \mathrm{s}) . C_{P}=$ Power coefficient. $P_{\text {rotor }}$ =Extracted power.

$P$ wind $=$ Power in wind

\subsection{Permanent Magnet Synchronous Generator (PMSG) Model}

The dynamic model of PMSG can be represented in the Park's (d, q) system using the following equations (12-14):

$\left[\begin{array}{l}v_{d} \\ v_{q}\end{array}\right]=-\left[\begin{array}{cc}R_{s} & 0 \\ 0 & R s\end{array}\right]\left[\begin{array}{c}I_{d} \\ I_{q}\end{array}\right]-\left[\begin{array}{cc}L_{s} & 0 \\ 0 & L s\end{array}\right] \frac{d}{d t}\left[\begin{array}{c}I_{d} \\ I_{q}\end{array}\right]-w_{e}\left[\begin{array}{cc}0 & -L_{q} \\ L_{d} & 0\end{array}\right]\left[\begin{array}{c}I_{d} \\ I_{q}\end{array}\right]+w_{e}\left[\begin{array}{c}0 \\ \Psi_{m}\end{array}\right]$

Where

$R_{S}$ is the stator resistance $(\Omega) L d$ and $L q$ are the inductances $(H)$ of the generator on the $\mathrm{d}$ and $\mathrm{q}$ axis respectively $\Psi_{m}$ is the permanent magnetic flux $(W b)$ and $W e$ is the electrical rotating speed $(\mathrm{rad} / \mathrm{s})$ of the generator, defined by:

$w_{e}=\mathrm{P} \times \mathrm{Wm}$

The number of generating pole pairs is denoted by $\mathrm{P}$. The electromagnetic torque equation is calculated as follows:

$C_{e m}=\frac{3}{2} \mathrm{p}\left[\left(L_{d}-L_{q}\right) I_{d} I_{q}-\Psi_{m} I_{q}\right]$

design of the construction Wind Turbine Generator is shown in Fig 4. 


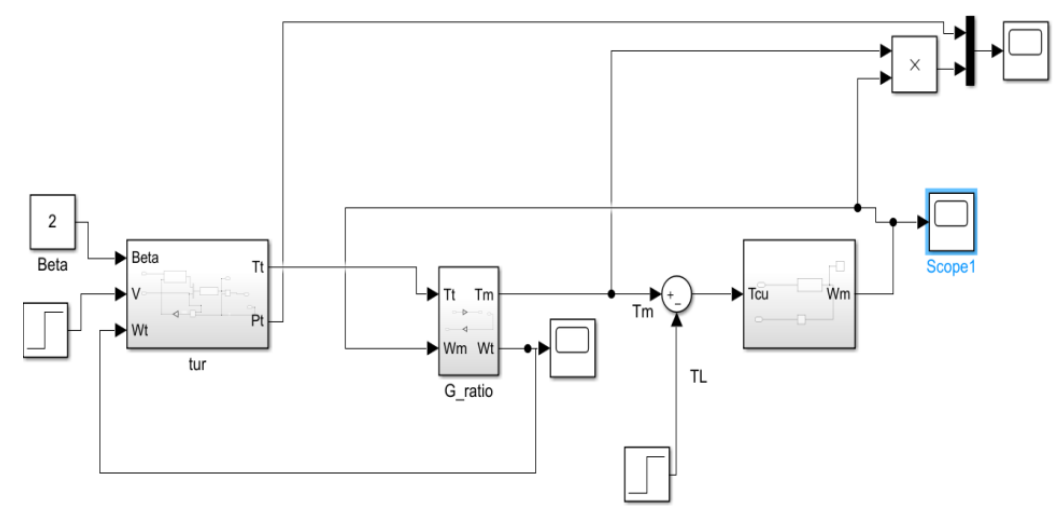

Fig 4. Wind Turbine Generator construction using MATLAB /Simulink

\section{Methodology}

Figure 5 depicts the planned smart energy management system for the smart grid. Two different units make up the generation system: a PV modular unit and a tiny wind turbine directdrive PMSG unit. On the other hand, the load side has a number of DC units with varying power ratings. To provide a constant supply of power to the load, the two units (supply-demand) are connected via a direct DC line system. However, a hybrid energy system (HES) with multiple types of renewable energy sources should be established to provide a continuous supply of power when renewable energy sources are unavailable. One of the primary issues that the HES faces is the capacity to meet load demand even when the generated electricity from renewable energy sources varies dramatically owing to weather conditions. Another issue that these HES have to deal with is keeping the voltage and frequency ratings within acceptable levels. The Smart grid is made up of several Microgrids, each of which is made up of multiple Nano grids. There are two types of control in a Nano grid structure: supply-side management (SSM) and demand-side management (DSM) (DSM). Photovoltaic modules, small-scale wind turbines, batteries, the utility grid, and other power sources are examples of supply for the Nano grid. The demand is the amount of energy consumed by household loads such as refrigerators, televisions, and heaters. Both supply and demand are extremely volatile, typically fluctuating between maximum and minimum consumption/production in a single day.

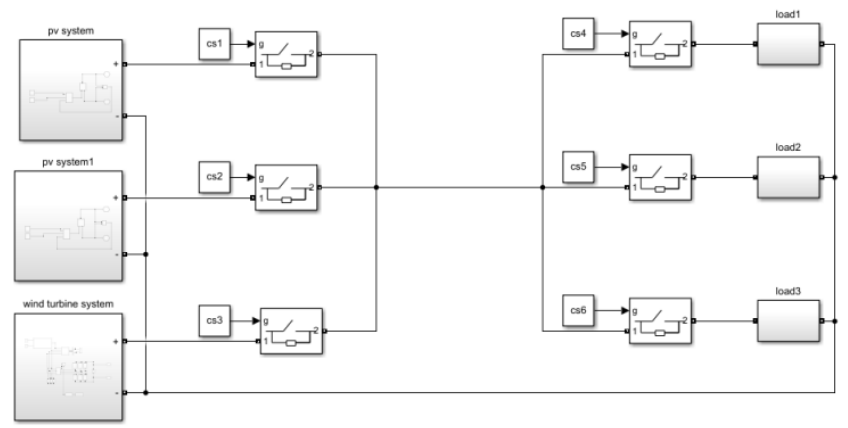


Fig 5. smart energy management system.

Unfortunately, in an unregulated Nano grid system, high consumption and production times rarely coincide. As a result, supply/demand management is an important component of Nano grid control. Supply-side management is used to improve the behaviour of the Nano grid's power sources in order to best match power production to the consumption curve and to maximise the utilisation of renewable energy sources. Demand-side management is used to match the power output of the Nano grid's sources to the consumption curve of the Nano grid's loads. It is feasible to develop and promote new energy services to address national society's challenges, such as the continual rise in energy demand, avoiding power peaks, and dealing with future trends. This can be accomplished by creating energy IoT-based energy management services, distributed energy paradigm development, and energy grid-based energy trading services[34]. To enable smart grid interoperability and other extra services, it is important to design a web connectivity service implementation environment. Master nodes serve as a centralised controller and manager for Microgrids, collecting data from all Nano grids (slave nodes) on the system's power output and consumption. All control decisions are made from a master node. If any Nano grids (slave nodes) are in short supply and require additional power, the master node will look for a suitable slave node to fill the gap. The master node reads parameters in real time, allowing the system to respond quickly to commands. And a slave node that represents homes, buildings, and other structures that have renewable energy sources by using sensors to measure voltage, current, power consumption, and power production, and a parameter called needed power if the node can't meet the demand and the load is above its maximum capacity. The slave node, on the other hand, receives signals from a master node in the event that another slave node requires power, and then uploads the requisite order to the internet's cloud. The master node can then read it and act in accordance with the reads, since IoT is a wide-ranging system of everyday detailed things connected to the internet that are capable of identifying themselves and informing data to objects on an internet network. When the slave node is connected to the internet, it begins to read sensor values, voltage, and current, as well as calculate power, extra power, which represents the power of the node that is not in use and can be shared with the node that is, and needed power, which represents the power required to meet the node's needs due to a power shortage. It can be calculated by subtracting consumed power from System capacity, which is the maximum power the system can generate, and needed power, which represents the power required to. After computing these numbers, it uploads them to the cloud through the internet. The slave node continuously checks for a signal from the master node indicating that their node requires power, as shown in Fig. 6. 


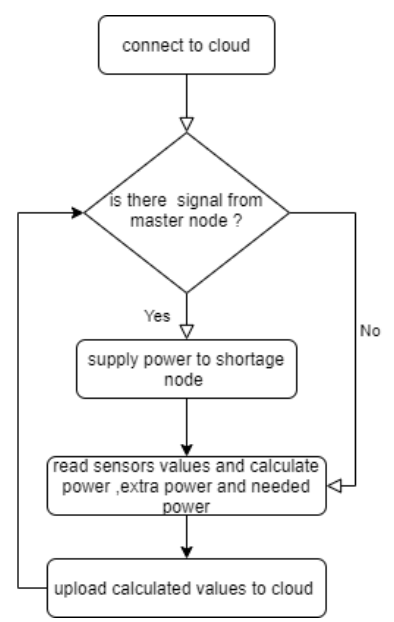

Fig. 6. Flow-chart of slave operation

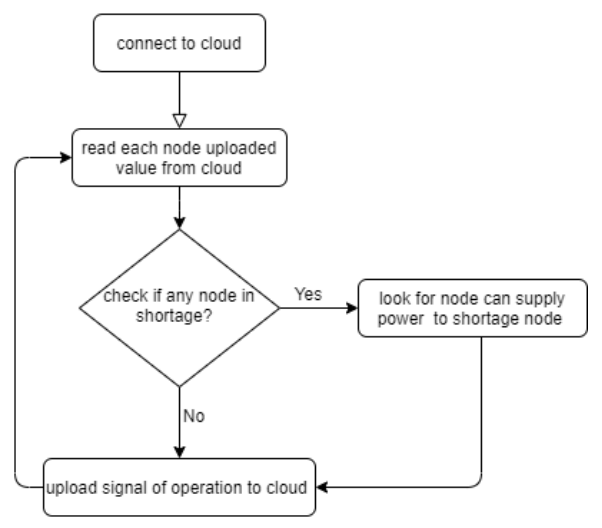

Fig 7. Flow diagram master node operation.

After being connected to the internet, the master node functions as a management, control, and balance system. It begins by reading the voltage, current, power, extra power, and needed power values of each node from the cloud. The most crucial values are needed power and extra power, which indicate whether the node is in low supply and whether it can supply power to neighbouring nodes. The Master node will first check each node's required power value; if any node's required power value is more than zero, the node is in need of power. The second step is to select a suitable node that can deliver the required power to the node by comparing the additional power values of each node to the required power of the shortage node. It will update the operation signal that determines which node will provide electricity. Every time the slave nodes update their values to the cloud, they verify this signal. Figure 7 depicts the flow diagram for a master node.

\section{Thing speak of IoT Web Service}


Things talk is a web-based open API IoT source information platform that stores sensor data from various 'IoT apps' and conspires the detected data output in graphical form at the web level. Thing speak communicates with the help of an internet connection that acts as a 'data packet' carrier between the connected 'things' and the Thing speak cloud, retrieving, saving/storing, analysing, observing, and working on the sensed data from the connected sensor to the host microcontroller such as an Arduino, TI CC3200 module, Raspberry-pi, and so on. The Thing Speak aids in the formation of enthralling sensor-based logging applications, location/place tracing applications, and a'social network' of objects/things with updated status, and we can also have control over 'Home automation' products that are connected to the public domain network (via the Internet) from the location of existing and potential customers. The word 'Channel,' which has a field for data, a field for location, and a field for status for various sensed data, is the most important component of Thing Talk functionality. Once the channels have been constructed in 'Thing talk,' the data can be implemented_or the data may be processed and visualised using MATLAB, and the data can be responded to with tweets and other forms of notifications [35]. Thing talk also has a function that allows you to construct a public-based channel that you can use to analyse and evaluate it. To engage the 'Things/objects' in sensing the respective data and transmitting across the Internet, one must go beyond simply connecting data from a PC, objects to collect (sensors), and to do so, data must be network uploaded that are in the form of servers (that run applications), and such types are referred to as Cloud. The 'Cloud' employs graphical visualisation operations and is available in the form of a virtual server for users. Objects communicate with the cloud via possible 'wireless internet connections' available to users, with the majority of objects relying on sensors/actuators to provide information about our environmental analogy data. The Internet of Things (IoT) helps to connect everything and allows us to communicate with our own devices, as well as allowing objects/things to interact with each other. [36-37].

\section{Results}

Based on MATLAB/Simulink software, a model of the smart energy management system has been constructing $\mathrm{t}$ for each master and slave node with all connected power supply and loads as shown in Fig 9. The system has been tested for all-day intervals and under different load variation conditions as explained in Fig 10. From the results shown in previous figures, it's clear that the suggested smart system has a high ability to monitor, compute and control the generated power from PV and wind generator to supply the load connected at the terminal of the DC bus. and measurements values each node will have its renewable source PV or wind turbine and microcontroller to measure the voltage using a voltage divider to measure the voltage of the source and current sensor for measure current across the load of the node and calculate the power consumption of the node. The extra power and needed power are calculated since each node has a max power value. It can say if the power consumption of the node is greater than max power the node is in shortage and need power and if the power consumption of the node is less than max power the node has the extra power to shear in case other nodes need. 


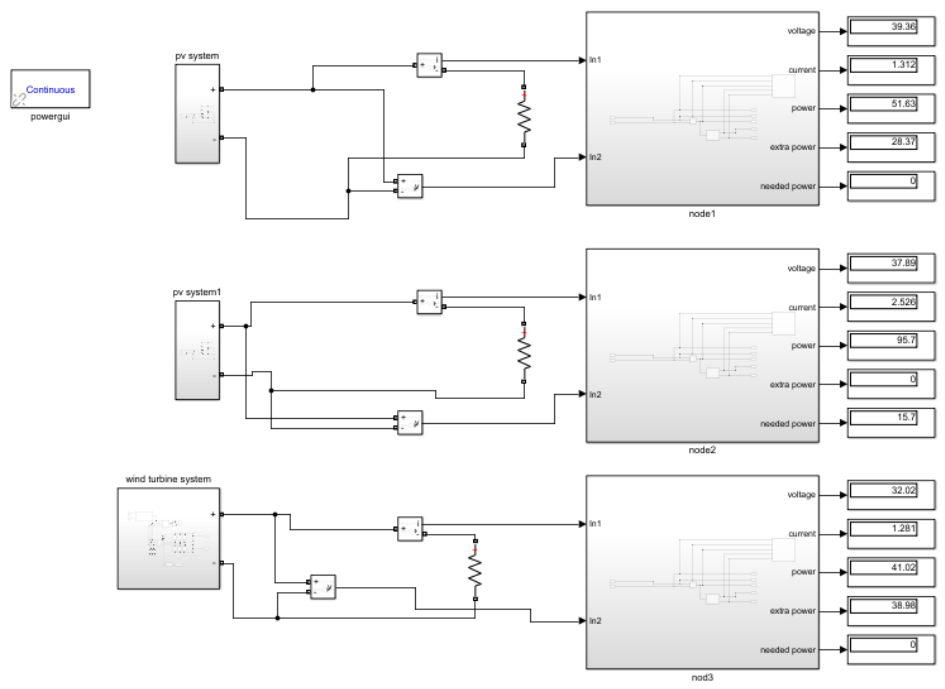

Fig 9. MATLAB/Simulink of nodes and reading

Once the node has switched on and connected to Thing Speak it starts to upload variation in the generated and consumed power to its channel as in Fig 11. The status channel is the master node updated after reading all nodes values if any node needs power. In this case, the master node will look for a suitable node to provide needed power and update the status channel both the needed node and provider node will change to 1 in which, each slave node continuous read its status from corresponding flew in the status channel.

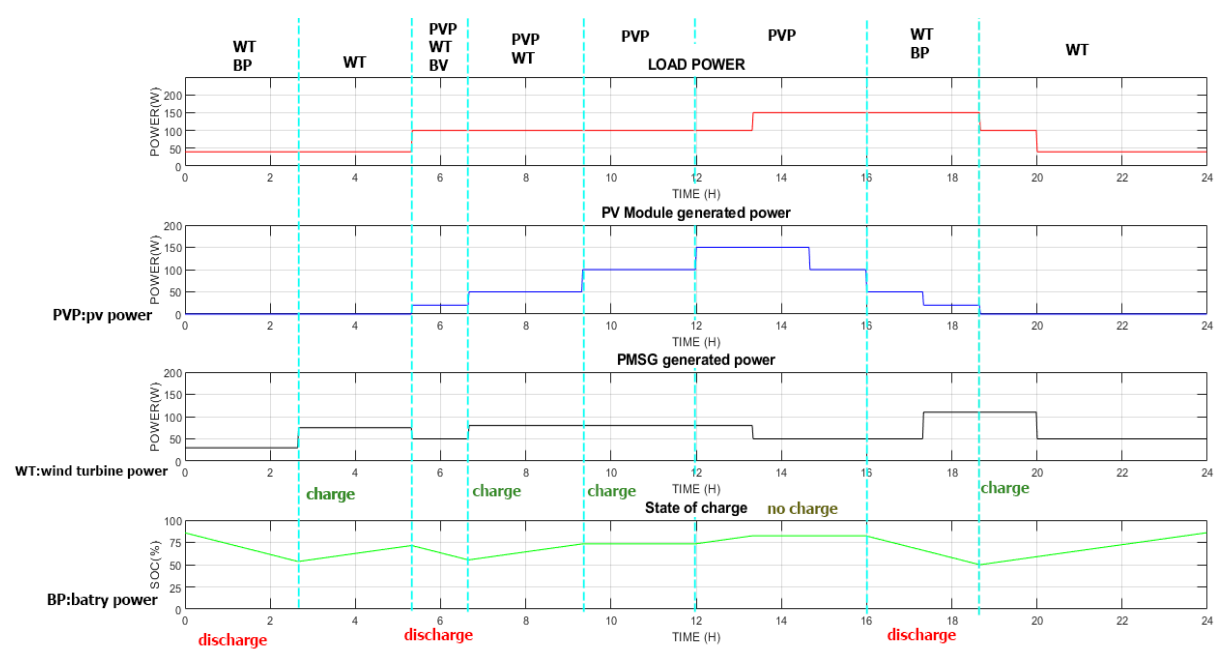

Fig 10. Variations of load with generated power. 


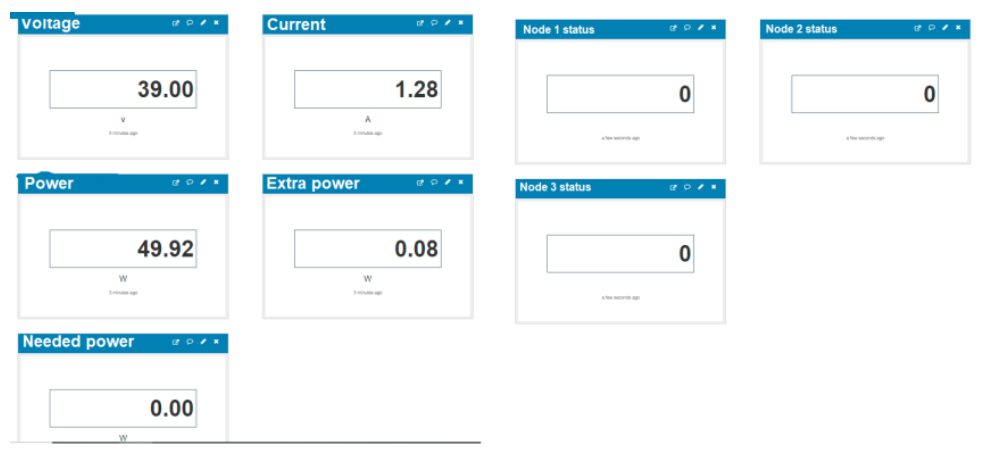

Fig 11. Node1 channel and status channel.

Fig 12. shows master node reading all nodes values from the cloud, by accessing to node's channel and read the uploaded values, by checking the extra power and needed power values for each node and check if any node had needed power value more than zero if so this node has shortage in power the master node immediately check other nodes extra power values and Comparing with needed power of node which needs power if it was bigger than the needed power this node will supply power to the node else it will check another node, after selecting shortage node and provider node operation signal will upload to status channel, as shown in Fig 12 there is no node need for power the status channel and its fields will remain 0 . The master node will check if there is any node that had extra power to transmitted to node 3 node 2 can supply the needed power. Below is the table with parameters from each node channel and status channel.

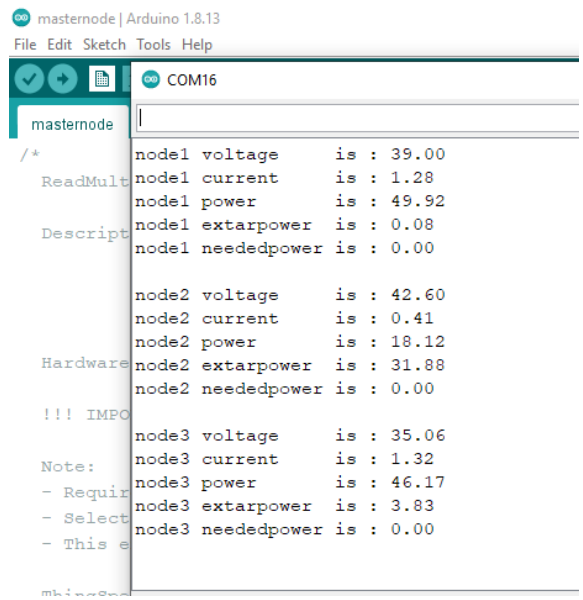

Fig 12. Master node reading all node values. 
Table 1. Master node reading along with status signal

\begin{tabular}{|c|c|c|c|c|c|c|c|c|}
\hline $\begin{array}{c}\text { Node } \\
\text { Number }\end{array}$ & Voltage & Current & Power & $\begin{array}{l}\text { Extra } \\
\text { Power }\end{array}$ & $\begin{array}{c}\text { Needed } \\
\text { Power }\end{array}$ & Status & Time & $\begin{array}{c}\text { Measure } \\
\text { No. }\end{array}$ \\
\hline Node1 & 39 & 1.28 & 49.92 & 0.08 & 0 & 0 & $12: 04: 35$ & \multirow{3}{*}{1} \\
\hline Node2 & 42.6 & 0.41 & 18.12 & 31.88 & 0 & 0 & $12: 04: 35$ & \\
\hline Node3 & 35.06 & 1.32 & 46.17 & 3.83 & 0 & 0 & $12: 04: 36$ & \\
\hline Node1 & 39 & 1.28 & 49.92 & 0.08 & 0 & 0 & $12: 04: 40$ & \multirow{3}{*}{2} \\
\hline Node2 & 42.6 & 0.41 & 18.12 & 31.88 & 0 & 1 & $12: 04: 41$ & \\
\hline Node3 & 31.86 & 2.46 & 78.47 & -28.47 & 28.47 & 1 & $12: 04: 40$ & \\
\hline Node1 & 39 & 1.28 & 49.92 & 0.08 & 0 & 0 & $12: 04: 45$ & \multirow{3}{*}{3} \\
\hline Node2 & 34.92 & 1.3 & 45.4 & 4.6 & 0 & 1 & $12: 04: 46$ & \\
\hline Node3 & 35.2 & 1.42 & 49.88 & 0.12 & 0 & 1 & $12: 04: 45$ & \\
\hline Node1 & 37.32 & 0.37 & 13.925 & 36.07 & 0 & 1 & $12: 04: 51$ & \multirow{3}{*}{4} \\
\hline Node2 & 46.05 & 0.51 & 23.485 & 26.5145 & 0 & 0 & $12: 04: 51$ & \\
\hline Node3 & 33.341 & 1.9035 & 63.467 & -13.4672 & 13.46724 & 1 & $12: 04: 52$ & \\
\hline Node1 & 35.21 & 0.9254 & 32.58 & 17.41 & 0 & 1 & $12: 05: 03$ & \multirow{3}{*}{5} \\
\hline Node2 & 46.05 & 0.51 & 23.485 & 26.5145 & 0 & 0 & $12: 05: 00$ & \\
\hline Node3 & 35.0586 & 1.3169 & 46.1716 & 3.82833 & 0 & 1 & $12: 05: 01$ & \\
\hline Node1 & 37.3210 & 0.3731 & 13.9251 & 36.0749 & 0 & 0 & $12: 05: 13$ & \multirow{3}{*}{6} \\
\hline Node2 & 45.72 & 0.46 & 21.0312 & 28.9688 & 0 & 0 & $12: 05: 10$ & \\
\hline Node3 & 36.0767 & 1.0628 & 38.3436 & 11.65638 & 0 & 0 & $12: 05: 16$ & \\
\hline
\end{tabular}

\section{Practical implementation of Smart Energy System}

To validate the simulated model, a complete system is shown in Fig. 13 is constructed. The following components make up the hardware system. A relay is a switch that is controlled by electricity. It has a set of input terminals for one or more control signals, as well as a set of working contact terminals. When the node needed power the master node sends an upload operation signal to the cloud the node reads this signal and if there is a node that can provide the power relay is open and allow the power flow to the load and supply to the required power. A voltage divider is a type of passive linear circuit that generates an output voltage (Vout) that is a fraction of the input voltage (Vin). The outcome of dividing the input voltage among the divider's components called voltage division. Two resistors are linked in series to form a voltage divider, with the input voltage applied across the resistor pair and the output voltage emerging from the connection between them. Voltage dividers made of resistors are frequently used to lower the magnitude of a voltage so that it may be measured. The current sensor from ACS712 works on the Hall Effect to measure electric current. This sensor can detect both direct current (DC) and alternating current (AC). The microcontroller is an important part of the system, each node has its microcontroller which is used to Measures different parameter in the system. This work we use Arduino Uno which is microcontroller has analog and digital pins to read or write from/to and each system has pre-defined maximum system capacity(MSC) .all slave nodes should 
Measures voltage, current, power and then calculate extra power and needed power and continuously check operation signal from status channel, using voltage divider which is Circuit use to Measure more than $5 \mathrm{v}$, then measuring the current using current sensor .calculate power, extra power(EP) and needed power(NP) using the following eq. (15-17)

$\mathrm{P}=\mathrm{V} . \mathrm{I}$

$\mathrm{EP}=\mathrm{MSC}-\mathrm{P}$

If EP was a negative value this indicates that node needs the power to calculate how much power the system want

$\mathrm{NP}=\mathrm{P}-\mathrm{MSC}$

These values need to be uploaded to the cloud to be read by the master node the Arduino connects to the internet using esp8266 Wi-Fi that connects Arduino to the cloud to uploaded calculated values and read operation signal from the status channel and check to wither to open relay or not. Fig 14. shows slave node components. For the master node, the node MCU microcontroller is used as shown in Fig 15., since the master node has no measure operation it's only a software operation. the node MCU connects to the internet and accessing to slave node values starts to save these values in the node MCU . after complete read operation next step is to check if there any node needs power, the master node check if the NP is more than zero this means the node need power and look of suitable node has enough power to supply by checking EP if it more than the needed power NP, for example, if node1 has shortage in power the NODE1.NP will be more than zero so the master node will make a Comparison between NODE1.NP and NODE2.EP

IF NODE1.NP < NODE2.EP then node 2 will provide power to node 1

IF NODE1.NP < NODE3.EP then node 3 will provide power to node 1

The final step is to updating status channel values to send a signal to the node to open or Close really to supply or Receive Power.

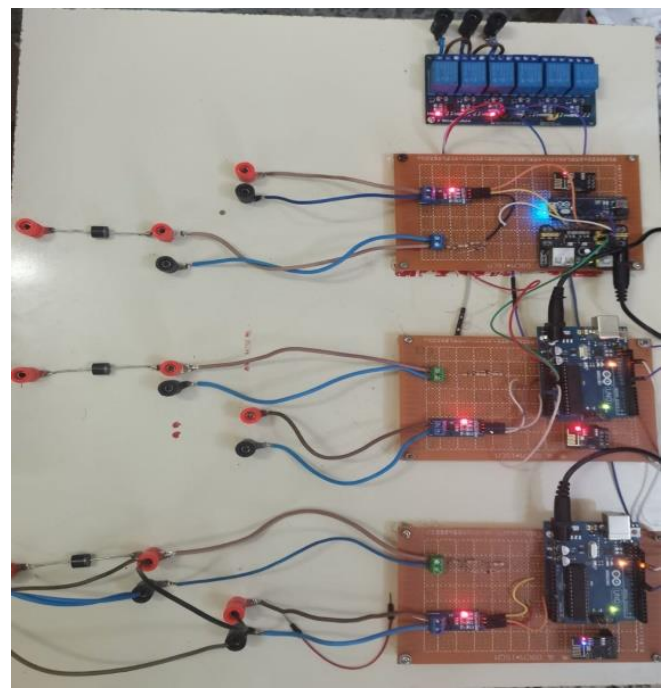


Fig 13. Energy management control unit based on Arduino.

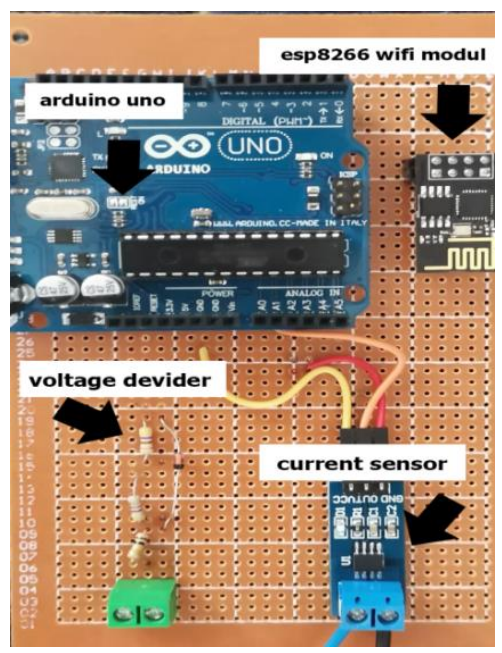

Fig 14. slave node component

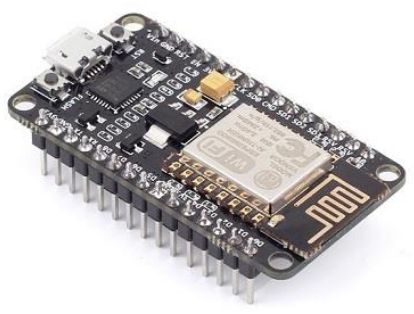

Fig 15. Nodmcu Master Node

\section{Conclusion}

This paper presents smart energy management for wind-solar hybrid systems for microgrids using IoT. A hybrid system helps in augmenting the level of renewable generation from the available level of resources. Integration of renewable energy resources can be helpful in commercial areas where there is a large electricity demand. Since renewable energy resources are incorporated there are no negative impacts on nature. The invariability in the output that is obtained while operating as a single source is also reduced to a large extent. When an IoT energy management system is incorporated it will increase the efficiency of energy available. The extent up to which the efficiency is improved depends on the renewable energy source used. Also increases the reliability and economics of energy supply. This system also promises quicker energy restoration after power disturbances. Using Microcontroller Arduino and 'Thing Speak' cloud to allow nodes to send and receive parameters and signals, slave node sends upload their parameter to 'Thing Speak' cloud channel and the master node will read this parameter and determine whether node need power or not and if so master node look for a suitable node to supply power from by sending a signal to both nodes. the system has been tested in Simulink using MATLAB and expectantly the result was a match, and the object of the system has been achieved, power-sharing and balancing between nodes help decrease demand power from the utility grid and decrease the cost of electrical power.

\section{References}

[1] Photovoltaic and Wind Turbine Generation System for Constant Power Supply with IoT-based Monitoring and Control,2018

[2] Atika Qazi et al., "Towards Sustainable Energy: A Systematic Review of Renewable Energy Sources, Technologies, and Public Opinions", IEEE Access, vol. 7, pp. 63837 - 63851, May 2019. 
[3] Trieu Mai et al., "Renewable Electricity Futures for the United States" IEEE Trans. on Sustainable Energy, vol. 5, no. 2, pp. 372-378, Apr. 2014.

[4] M. H. Nehrir et al., "A Review of Hybrid Renewable/Alternative Energy Systems for Electric Power Generation: Configurations, Control, and Applications" IEEE Trans. on Sustainable Energy, vol. 2, no. 4, pp. 392-403, Oct. 2011.

[5] Pranav M.S et al., "Hybrid Renewable Energy Sources (HRES) - A Review" International Conference on Intelligent Computing, Instrumentation and Control Technologies (ICICICT) 2017, pp.162- 165.

[6] Xiaotong Song et al., "Reliability Varying Characteristics of PV-ESSBased Standalone Microgrid", IEEE Access, vol. 7, pp. 120872- 120883.

[7] A.A. Jamali et al., "Energy storage systems and their sizing techniques in power system- A review" IEEE Conference on Energy Conversion (CENCON), 2015, pp.215-220.

[8] Caisheng Wang et al., "From hybrid energy systems to microgrids: Hybridization techniques, configuration, and control”, IEEE PES General Meeting, USA, pp. 1-4, Jul. 2010.

[9] Saroja Kanti Sahoo et al., "Control Techniques in AC, DC, and Hybrid AC-DC Microgrid: A Review", IEEE Journal of Emerging and Selected Topics in Power Electronics, vol. 6, iss. 2, pp. 738-759, Jun. 2018.

[10] Venkata Yaramasu et al., "High-power wind energy conversion systems: State-of-the-art and emerging technologies", Proceedings of the IEEE, vol. 103, iss. 5, pp. 740-788, May, 2015.

[11] M. Ryu, H. Kim, J. Kim, J. Baek, J. Jung, Test bed implementation of 380V DC distribution system using isolated bidirectional power converters, in: IEEE Energy Conversion Congress and Exposition (ECCE), 2013, pp. 2948-2954.

[12] B.A. Thomas, Edison revisited: impact of DC distribution on the cost of LED lighting and distribution generation, in: 27th Annual IEEE Applied Power Electronics Conference and Exposition (APEC), 2010, pp. 588-593.

[13] W. Yu, J.-S. Lai, H. Ma, C. Zheng, High-efficiency DC-DC converter with twin bus for dimmable LED lighting, IEEE Trans. Power Electron. 26 (2011) 2095-2100.

[14] A. Al-Diab, C. Sourkounis, Integration of flywheel energy storage system in production lines for voltage drop compensation, in: IEEE 37th Annual Conference Industrial Electronics (IECON), 2011, pp. 3882-3887.

[15] B.H. Kenny, R. Jansen, P. Kascak, T. Dever, W. Santiago, Integrated power and attitude control with two flywheels, IEEE Trans. Aerosp. Electron. Syst. 41 (2005) 1431-1449

[16] Ren21, Renewables. "Global statusreport." Renewable energy policy network for the 21 st century. http://www.ren21.net [accessed June 1, 2018].

[17] Elsayed Ahmed T, Mohamed Ahmed A, Mohammed OA. DC microgrids and distribution systems: an overview. Electr Power Syst Res 2015;119:407-17

[18] Planas E, Andreu J, Gárate JI, Martínez De Alegría I, Ibarra E. AC and DC technology in microgrids: a review. Renew Sustain Energy Rev 2015;43:726-49.

[19] Microgrid Opportunity: What Stands in the Way for 2017? - Renewable Energy World http://www.renewableenergyworld.com/articl es/2017/01/microgridopportunity-whatstands-in-theway-for-2017.html [accessed October 29, 2016].

[20] P. Pawar, M. TarunKumar, P. Vittal K, An IoT based Intelligent Smart Energy Management System with Accurate Forecasting and Load Strategy for Renewable Generation, Measurement (2019), doi: https:// doi.org/10.1016/j.measurement.2019.107187

[21] Ranhotigamage, Chagitha, and Subhas Chandra Mukhopadhyay."Field trials and performance monitoring of distributed solar panels using a low-cost wireless sensor network for domesticapplications." IEEE Sensors Journal11.10 (2011): 2583-2590.

[22] Constantin, Suciu, et al. "GPRS based system for atmosphericpollution monitoring and warning." Automation, Quality andTesting, Robotics, 2006 IEEE International Conference on. Vol.2.IEEE, 2006.

[23] Reddy, S. R. N. "Design of remote monitoring and control systemwith automatic irrigation

[24] Prakhar Srivastava, Mohit Bajaj, Ankur Singh Rana." IOT Based Controlling of Hybrid Energy System using ESP8266" 2019.

[25] P. Pawar, M. TarunKumar, P. Vittal K, An IoT based Intelligent Smart Energy Management System with AccurateForecasting and Load Strategy for Renewable Generation, Measurement (2019). 
[26] S. Lyden, M. E. Haque, A. Gargoom, M. Negnevitsky, and P. I. Muoka, "Modelling and Parameter Estimation of Photovoltaic Cell," in Universities Power Engineering Conference (AUPEC), 2012 22nd Australasian, 2012, pp. 1-6.

[27] N. Pandiarajan and R. Muthu, "Mathematical modeling of photovoltaic module with Simulink," in 2011 1st International Conference on Electrical Energy Systems, ICEES 2011, 2011, no. Icees, pp. 258-263.

[28] M. Edouard and D. Njomo, "Mathematical Modeling and Digital Simulation of PV Solar Panel using MATLAB Software," vol. 3, no. 9, pp. 24-32, 2013.

[29] H. Mahamudul, M. Saad, and I. Henk, "A Modified Simulation Method of Photovoltaic Module in Simulink Environment," no. 1, pp. 607-610, 2012.

[30] T. Marnoto, K. Sopian, W. A. N. Ramli, and W. A. N. Daud, "Mathematical model for determining the performance characteristics of multi-crystalline photovoltaic modules," International Conference on Mathematical and Computational Methods in Science and Engineering , pp. 79-84, 2007.

[31] Dr.P.Sangameswar Raju, Mr. G. Venkateswarlu, "Simscape Model Of Photovoltaic cell", International Journal of Advanced Research in Electrical, Electronics and Instrumentation Engineering, Vol. 2, Issue 5, May 2013.

[32] M. Vyas, M. Singh, and S. Santoso,, "Handbook Of Wind Power System", Springer, 2011.

[33] Thomas Ackerman, "Wind Power In Power Systems", Royal Institute of Technology Stockholm, Sweden, Edition: John Wiley and sons, Ltd, 2005.

[34] T. Burton, D. Shape, N. Jenkins, E. Bossany, "Wind Energy Handbook", J. Wiley \& Sons, Ltd. 2001.

[35] ThingSpeak - an API and Web Service for the Internet of Things, a published paper

[36] ThingSpeak: Open Source Platform for Connected Products and Services(PR Newswire)

[37] The open data platform for the Internet of Things.https://thingspeak.com (2015) 